\title{
Influence of the initial prestressing on the crack resistance of the self-stressed members reinforced with steel and FRP bars
}

\author{
Volha Semianiuk ${ }^{1, *}$, Viktar Tur $^{1,2}$, and Siarhei Semianiuk ${ }^{3}$ \\ ${ }^{1}$ Brest State Technical University, Department of Concrete Technology, 224017 Moskovskaya, 267, Brest, Belarus \\ ${ }^{2}$ Bialystok University of Technology, Department of Architecture and Building Structures, 15-351 Wiejska, 45E, Bialystok, Poland \\ ${ }^{3}$ Brest State Technical University, Civil Engineering Faculty, 224017 Moskovskaya, 267, Brest, Belarus
}

\begin{abstract}
Fiber reinforced polymer (FRP) bars are widely utilized in the civil engineering practice and characterized by the number of advantages, among them are the following: high strength-to-density ratio; absence of corrosion; resistance to the negative influence of the different aggressive mediums. Nevertheless, a wide practical application of such a bars finds an embarrassment because of the law modulus of elasticity (in the diapason from $30 \mathrm{GPa}$ to $60 \mathrm{GPa}$ ), that in its turn lead to the development of the excessive crack opening as well as deflections under the loading. To enhance structural performance of the FRP reinforced concrete members, pretensioning of FRP bars can be considered as a good option. Opposite to the concrete members mechanical pretensioning, physico-chemical method of bars pretensioning based on the selfstressing concrete utilizing is considered. Influence of the controlled initial stress-strain state obtained during early age concrete expansion on the mechanical resistance of the self-stressed concrete members reinforced with both steel and FRP bars was studied. Comparison of the prestressing effectiveness of the self-stressing concrete members with steel and FRP bars was performed. Proposition for effective utilizing of the FRP bars in the self-stressed concrete members was formulated based on results of the presented investigation.
\end{abstract}

\section{Introduction}

In the two last decades application of FRP bars in building industry has developed intensively due to its advantages, especially, in structures that are exposed to the influence of the aggressive environment and other special conditions (bridge deck slabs, industrial pavements and etc.). However, in spite of high tensile strength to density ratio and corrosion resistance, the main problems for the use of FRP bars as a structural reinforcement are connected with development of exceeding deflections as well as crack opening under service loads. One of the most effective methods to enhance its performance is pretensioning of the FRP bars. As it was stated in [1], physico-chemical method of reinforcing bars pretensioning based on the self-stressing concrete utilizing is considered as a good alternative to mechanical prestressing that characterized by the higher laboriousness, necessity in special equipment and devices as well as qualified personnel. The actual problem for self-stressed concrete members practical design is consisted in the development both of the adequate and universal analytical model for the prediction of the initial stress-strain state obtained at the early age concrete expansion stage and resistance models described such a members behavior subjected to the bending (with and without axial force), shear, etc. Modified strains development model (MSDM) for self- stressed concrete members restrained expansion strains assessment at the anytime interval of the early age selfstressing concrete expansion stage was proposed by the authors $[1,2]$. The proposed model is extended on the different ratio of the any reinforcement type, and different reinforcement arrangement in the concrete cross-section as well as it allows to calculate early age induced strains for different types of the expansive concretes (shrinkage-compensating, self-stressing).

In general case, initial stress-strain state, obtained on the self-stressing stage, influences on the self-stressed member behavior under the static loading, mainly before cracking, as for traditional prestressed structures. Analysis of the numerous scientific papers [3, 4] in the field of the self-stressed structures has shown that such a members were investigated mainly on the concrete restrained expansion stage and only a limited data presents theoretical and experimental results about such a members (conventionally reinforced with steel bars) resistance under the loading. As it was pointed in $[5,6]$ because of the FRP low (close to the concrete) modulus of elasticity, FRP reinforcing bars can be effectively utilized with initial pretensioning only. Physico-chemical pretensioning of such a bars with self-stressing concrete can be considered as an effective method of the member prestressing. This paper presents theoretical and experimental results for self-stressed members resistance reinforced with FRP bars. Additionally, self-stressed

* Corresponding author: olgasiemieniuk@gmail.com 
beams reinforced with steel bars were tested for comparison of the effects from the obtained initial selfstressing on the concrete member resistance under the static loading in case of steel and FRP reinforcing bars utilizing. The main assessed parameters within static loading stage were flexural cracks width, deflections member curvature as well as the failure mode. Analysis of the generalized behavior of the self-stressed concrete members under the loading was performed with hereby proposed diagram method utilizing.

\section{Influence of the initial stress-strain conditions on the concrete members with different reinforcement type behaviour under the loading. Diagram method}

To analyze results obtained within static loading of the self-stressed beams with non-symmetric both FRP and steel reinforcement arrangement the $\left\langle M-\varepsilon_{r t, x}\right\rangle$ diagram was proposed (where $M$ is a bending moment; $\varepsilon_{r t, x}$ is a longitudinal tensile strain from the loading on depth of gravity center of the reinforcement in tension). The general view of the diagram is presented in the Fig. 1.

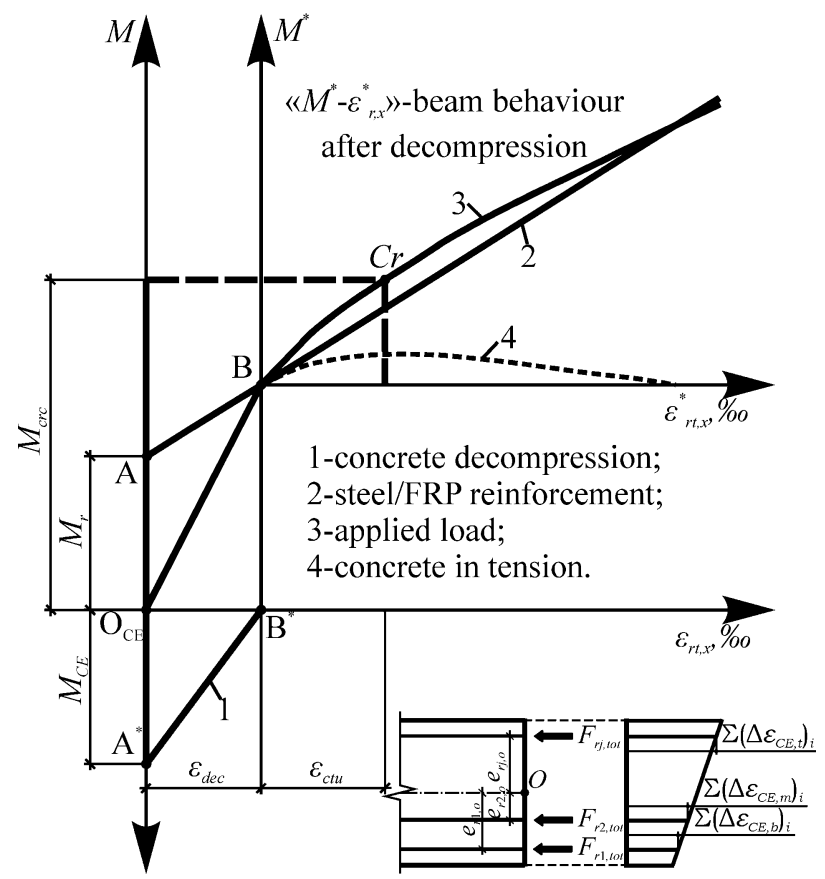

Fig. 1. Diagram for analysis of the initial stress-strain state influence on the behaviour under the loading of the nonsymmetrically reinforced beams.

Let's consider self-stressed beam under the monotonically increased load. Forces redistribution in the self-stressed beam cross-section under increasing load can be illustrated with the diagram presented in the Figure 1. Before load applying, in the beam cross-section balanced internal forces, obtained within self-stressing concrete expansion, are acting (see Fig. 1: $\mathrm{O}_{\mathrm{CE}} \mathrm{A}=\mathrm{O}_{\mathrm{CE}} \mathrm{A}^{*}$, $M_{C E}=M_{r}$ ). Moments from the internal forces, accumulated to the end of the self-stressing stage, respectively concrete cross-section gravity center can be determined with respect to the value of the fixed restrained strains in reinforcement:

$$
M_{C E}=M_{r}=\sum_{j=1}^{n} F_{r j, t o t} \cdot e_{r j, o}
$$

where: $M_{C E}$ and $M_{r}$ are the balanced moments from self-stressing;

$e_{r j, o}-$ eccentricity of the force in the $j$-th restraint reinforcement line respectively concrete crosssection gravity center;

$F_{r j, t o t}$ - force in the $j$-th restraint reinforcement line, accumulated on the self-stressing stage to the concrete expansion stabilization, that is determined as follows:

$$
F_{r j, t o t}=\varepsilon_{r j}\left(t_{t o t}\right) \cdot E_{r} \cdot A_{r},
$$

where: $\varepsilon_{r j}\left(t_{\text {tot }}\right)-$ strain in the $j$-th restraint reinforcement line, accumulated on the self-stressing stage to the concrete expansion stabilization, calculated in accordance with MSDM model [1, 2, 5];

$E_{r}, A_{r}$ - modulus of elasticity and area of the restraint reinforcement respectively.

After applying and further monotonically increasing of the load, reducing of the initial concrete cross-section precompression, obtained on the self-stressing stage, was observed. Besides, up to decompression point $\mathrm{B}^{*}$ (see diagram in the Fig. 1), cross-sectional tensile force is sustained by the reinforcement only (like it is in the traditional prestressed structures, line AB). Increment of the strains in reinforcement and increment of the bending moment, sustained by the reinforcement, before concrete decompression point $\mathrm{B}^{*}$ is characterized by the $\mathrm{AB}$ line on the diagram in the Fig. 1. At the same time, reducing of the concrete initial compressive stresses corresponds to the internal moment changing along the $\mathrm{A}^{*} \mathrm{~B}^{*}$ line. At the point $B^{*}$ (see Fig. 1) concrete initial elastic compressive strains on the depth of gravity center of the reinforcement in tension reduces to 0 (so-called decompression stage). At the point $\mathrm{B}$, line $\mathrm{AB}$ has the common point with the line $\mathrm{O}_{\mathrm{CE}} \mathrm{B}$, characterized changing of the bending moment from the externally applied load. Within further loading after decompression point $\mathrm{B}^{*}$, behavior of the self-stressed member is the same like behavior of the conventional RC-beam without any initial prestressing (part of the diagram in the $« M^{*}$ $\varepsilon_{r t, x}^{*} \gg$ axises). At this loading stage, a tensile force in concrete cross-section is sustained together by the concrete in tension and reinforcement right up to the flexural cracks appearing. Flexural cracks appear when tensile strains in concrete exceeds its ultimate values $\varepsilon_{c t u}$ (see diagram in $\left\langle M^{*}-\varepsilon_{r t, x}^{*}\right\rangle$ axises in the Fig. 1).

Thus, to the flexural cracks formation, the total strains respect to cracking $\varepsilon_{r t, c r c}$ on the depth of reinforcement gravity center, is considered as a sum of 
decompression starins $\varepsilon_{d e c}$ and ultimate concrete tensile strains $\varepsilon_{c t u}$

Resultant value of the cumulative concrete elastic strains $\varepsilon_{C E, e l}\left(t_{s l}\right)$, that corresponds to the decompression strains $\varepsilon_{d e c}$ at the static loading should be calculated as follows:

$$
\varepsilon_{\text {dec }}=\varepsilon_{C E, e l}\left(t_{s l}\right)=\frac{\varepsilon_{C E, \text { eltot }}\left(t_{i}\right) \cdot E_{c, a w}\left(t_{i}\right)}{E_{c m, s l}},
$$

where: $\varepsilon_{C E \text {,eltot }}\left(t_{i}\right)$ - concrete elastic strains accumulated to the end of the expansion stage and saved in structural memeber immediately before loading. It have to be calculated in accordance with proposed MSDM model $[1,2]$;

$$
E_{c, a w}\left(t_{i}\right)-\text { «average-weighted» expansive }
$$
concrete modulus of elasticity, calculation procedure of it is presented in detail in [6];

$E_{c m, s l}-$ concrete modulus of elasticity to the static loading time; loading.

$$
t_{i} \text { - age of concrete immediately before static }
$$

\section{Experiments}

Experimental studies were carried out on two series of self-stressed concrete beams with different type of reinforcing bars. Experimental beams cross-section geometry with reinforcement areas and arrangement are shown in Fig. 2.

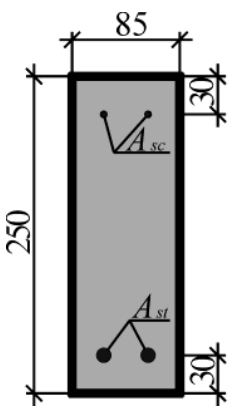

a)

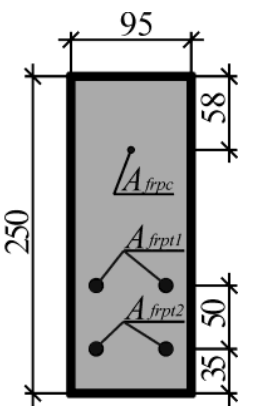

b) a) - self-stressed beams of the series I (I-BECS-(1...4): $A_{s C}=25,1 \mathrm{~mm}^{2}$ (2Ø4); $A_{s t}=157,0 \mathrm{~mm}^{2}(2 \varnothing 10)$;

b) - self-stressed beams of the series II (II-BECF- $(1,2)$ :

$A_{\text {frpc }}=13,7 \mathrm{~mm}^{2}(1 \varnothing 4) ; A_{\text {frpt } 1}=143,5 \mathrm{~mm}^{2}(2 \varnothing 10)$; $A_{\text {frpt } 2}=143,5 \mathrm{~mm}^{2}$ (2Ø10); II-BECF-(3): $A_{\text {frp }}=13,7 \mathrm{~mm}^{2}$ (1Ø4); $A_{\text {frpt1 }}=143,5 \mathrm{~mm}^{2}$ (2Ø10); $A_{\text {frpt2 }}=330,5 \mathrm{~mm}^{2}$ (2ø14))

Fig. 2. Experimental beams cross-section geometry with reinforcement areas and arrangement.

Expansive cement composition was consisted of 3 components in the following proportions (by weight): Portland cement (CEMI-42,5N) - $71 \%$; metakaolin powder - $14 \%$; gypsum powder $\left(\mathrm{CaSO}_{4} \cdot 2 \mathrm{H}_{2} \mathrm{O}\right)-15 \%$. The main physico-mechanical characteristics of the hardened expansive cement established in accordance

\begin{tabular}{|c|c|c|c|}
\hline \multicolumn{2}{|c|}{ Expansion } & \multicolumn{2}{|c|}{ Strength } \\
\hline $\begin{array}{l}\text { free expansion } \\
\text { strain } \varepsilon f, \%\end{array}$ & $\begin{array}{l}\text { reference } \\
\text { self-stress } \\
f_{C E, d, \mathrm{MPa}}\end{array}$ & $\begin{array}{c}\text { flexural } \\
f_{\text {flex }}, \mathrm{MPa}\end{array}$ & $\begin{array}{c}\text { compressive } \\
f_{c m}, \mathrm{MPa}\end{array}$ \\
\hline 1,21 & 5,9 & 4,5 & 40,8 \\
\hline \multicolumn{4}{|c|}{$\begin{array}{l}\text { Notes: } 1 . \text { Expansion and strength characteristics were established } \\
\text { at the } 28 \text { days age of the mortar bars hardened in the unrestrained } \\
\text { conditions; } \\
\quad \text { 2. Reference self-stress, } f_{C E, d} \text {, was established in standard } \\
\text { restraint conditions: } \rho_{l}=1 \% \text { and } E_{s}=200 \mathrm{GPa} \text {. }\end{array}$} \\
\hline
\end{tabular}
with $[7,8]$ are presented in Table 1.
Table 1. Expansive cement characteristics.

Self-stressed beams of the both series were made of self-stressing concrete with characteristics presented in Table 2.

\begin{tabular}{|c|c|c|c|c|}
\hline \multirow{2}{*}{ 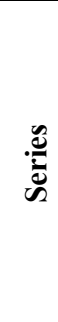 } & \multicolumn{2}{|c|}{$\begin{array}{c}\text { Expansion } \\
\text { characteristics } \\
\text { at the concrete } \\
\text { expansion stabilization }\end{array}$} & \multicolumn{2}{|c|}{$\begin{array}{c}\text { Mechanical } \\
\text { characteristics }\end{array}$} \\
\hline & $\begin{array}{c}\text { free } \\
\text { expansion } \\
\text { strain } \\
\varepsilon C E, f, \%\end{array}$ & $\begin{array}{l}\text { reference } \\
\text { self-stress } \\
f_{C E, d, \mathrm{MPa}}\end{array}$ & $\begin{array}{c}\text { compressive } \\
\text { strength } \\
f_{c m, 28}, \mathrm{MPa}\end{array}$ & $\begin{array}{l}\text { modulus } \\
\text { of } \\
\text { elasticity } \\
E_{c m, 28} \\
\mathrm{GPa}\end{array}$ \\
\hline I & 0,47 & 2,4 & 23,2 & 25,3 \\
\hline II & 0,55 & 2,8 & 27,8 & 25,7 \\
\hline \multicolumn{5}{|c|}{$\begin{array}{l}\text { Notes; 1. Free expansion strain, } \varepsilon_{C E, f} \text {, was established on } \\
\text { the unrestrained specimens; } \\
\text { 2. Reference self-stress, } f_{C E, d} \text {, was established in the } \\
\text { standard restraint conditions: } \rho_{l}=1 \% \text { and } E_{s}=200 \mathrm{GPa} \text {; } \\
\text { 3. Modulus of elasticity was established on the } \\
\text { cylindrical specimens }(\varnothing=150 \mathrm{~mm}, h=300 \mathrm{~mm}) \text {. }\end{array}$} \\
\hline
\end{tabular}

Table 2. Average values of the self-stressing concrete characteristics.

Steel and FRP reinforcing bars characteristics are listed in Table 3 and Table 4.

Table 3. Mechanical characteristics of steel reinforcing bars (experimental values).

\begin{tabular}{|c|c|c|}
\hline $\begin{array}{c}\text { Nominal } \\
\text { diameter, mm }\end{array}$ & $\begin{array}{c}\text { Yield stress } \\
\boldsymbol{f}_{\boldsymbol{y} \boldsymbol{m}}, \mathbf{M P a}\end{array}$ & $\begin{array}{c}\text { Modulus of elasticity } \\
\boldsymbol{E}_{\boldsymbol{s} \boldsymbol{m}}, \mathbf{G P a}\end{array}$ \\
\hline 4 & 573,2 & 200,0 \\
\hline 10 & 625,7 & \\
\hline
\end{tabular}

Table 4. Mechanical characteristics of FRP reinforcing bars (experimental values).

\begin{tabular}{|c|c|c|c|c|}
\hline $\begin{array}{c}\text { Nominal } \\
\text { diameter, } \\
\text { mm }\end{array}$ & $\begin{array}{c}\text { Type } \\
\text { of } \\
\text { fibers }\end{array}$ & $\begin{array}{c}\text { Modulus } \\
\text { of } \\
\text { elasticity } \\
\boldsymbol{E}_{\text {frpm }}, \mathbf{G P a}\end{array}$ & $\begin{array}{c}\text { Tensile } \\
\text { strength } \\
f_{\text {frpm }}, \\
\text { MPa }\end{array}$ & $\begin{array}{c}\text { Ultimate } \\
\text { tensile } \\
\text { strain } \\
\boldsymbol{\varepsilon}_{\text {frpm }}, \boldsymbol{\%}\end{array}$ \\
\hline 5 & Basalt & 51,5 & 1262 & 2,45 \\
\hline 10 & Glass & 45,2 & 1027 & 2,27 \\
\hline 14 & Glass & \multirow{2}{*}{$*$}
\end{tabular}

When self-stressing concrete of the series I and series II achieved compressive strength of $7,3 \mathrm{MPa}$ and $10,1 \mathrm{MPa}$ at average respectively, these beams were demolded and immediately after demolding were immersed in water and cured in this conditions until stabilization of concrete expansion was reached. Beam restrained strains were measured on the reinforcing bars 
depth by mechanical extensometer on the $450 \mathrm{~mm}$ base with $0,01 \mathrm{~mm}$ accuracy.

\section{Results}

\subsection{Expansion (self-stressing) stage}

Experimental values of the restrained strains and selfstresses in concrete on the depth of the cross-section gravity center immediately before static loading are listed in the Table 5.

Table 5. Experimental values of restrained strains and self-stresses immediately before static loading.

\begin{tabular}{|c|c|c|c|c|}
\hline & \multicolumn{3}{|c|}{ Restrained strains, [\%] } & $\begin{array}{c}\text { Self- } \\
\text { stres } \\
\text { Unit code }\end{array}$ \\
\cline { 2 - 5 } & $\Sigma\left(\Delta \varepsilon_{C E, t}\right)_{i}$ & $\Sigma\left(\Delta \varepsilon_{C E, m}\right)_{i}$ & $\Sigma\left(\Delta \varepsilon_{C E, b}\right)_{i}$ & $\begin{array}{c}\mathbf{s} \\
\boldsymbol{\sigma}_{C E_{1}} \\
{[\mathbf{M P a}} \\
\text { ] }\end{array}$ \\
\hline I-BECS-(1) & 0,342 & - & 0,128 & 2,69 \\
\hline I-BECS-(2) & 0,372 & - & 0,144 & 2,95 \\
\hline I-BECS-(3) & 0,443 & - & 0,144 & 3,00 \\
\hline I-BECS-(4) & 0,499 & - & 0,154 & 3,46 \\
\hline II-BECF-(1) & 0,481 & 0,330 & 0,269 & 1,78 \\
\hline II-BECF-(2) & 0,556 & 0,365 & 0,276 & 1,92 \\
\hline II-BECF-(3) & 0,429 & 0,267 & 0,197 & 2,10 \\
\hline
\end{tabular}

As it can be seen from the Table 5, all of the tested beams reached initial self-stresses from 1,8 to $3,5 \mathrm{MPa}$ depending on the type, area and arrangement of the reinforcing bars. Reached pretensioning in reinforcing bars were at average $46 \%$ from yield strain and $14 \%$ from ultimate tensile strain for steel and FRP reinforcing bars respectively. It should be pointed that for the members prestressed with FRP reinforcing bars in accordance with [9], initial values of the prestress should be limited by the $24 \%$ from the ultimate tensile strength.

Beams initial restrained expansion curvature values obtained on the basis of measured restrained strains varied in the diapason $(1,16-1,82) \cdot 10^{-5} \mathrm{~mm}^{-1}$. These values of the beams initial restrained expansion curvature obtained at the self-stressing stage should be considered as a result of two developed in time superposed basic processes: on one hand - self-stressing concrete expansion in non-symmetrical restraint conditions and on the other hand - concrete elastic compressive strains accumulating under monotonically increasing in time restraint reaction $[1,5,6]$. At the same time so-called beam initial «elastic» curvature (that is determined from the accumulated concrete elastic compressive strains distribution) only have an influence on the self-stressed member behaviour under the applied static load in terms of traditional decompression. In contrast with traditional prestressed members in the selfstressed members the values of the beam initial «elastic» curvature are not possible to establish based on the direct strains measurement, but it can be obtained in accordance with the proposed MSDM concept $[1,2]$.

\subsection{Load-deflection responses and failure modes}

After the self-stressing concrete expansion stabilization was reached, self-stressed beams were tested with monotonically increasing load by means of two concentrated forces applied at the $1 / 3$ and $2 / 3$ points of the $1200 \mathrm{~mm}$ span. The main aim of the static loading consisted in the investigation of the influence of the achieved initial stress-strain state obtained to the selfstressing concrete expansion stabilization on the behavior of the tested beams under the load.

The moment-curvature and moment-deflection curves for specimens of series I and series II are shown in Fig. 3.

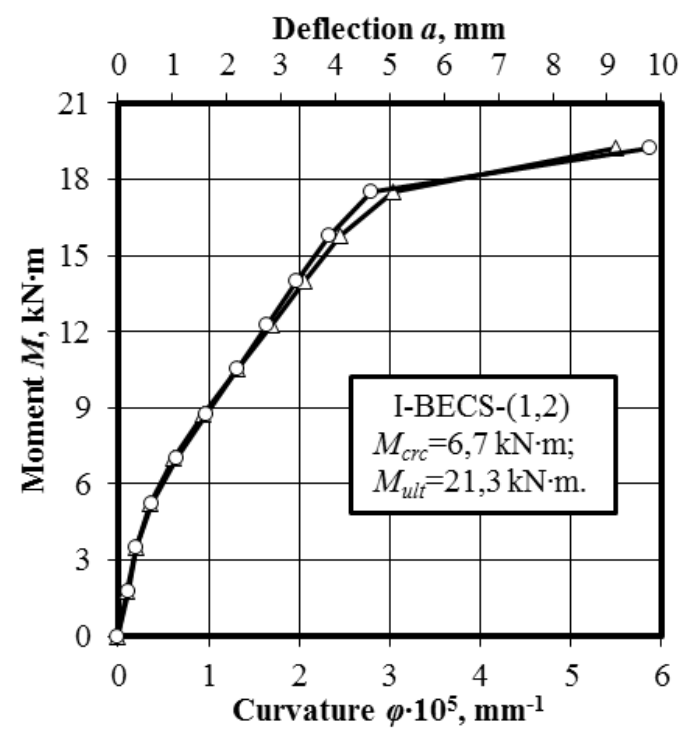

a)

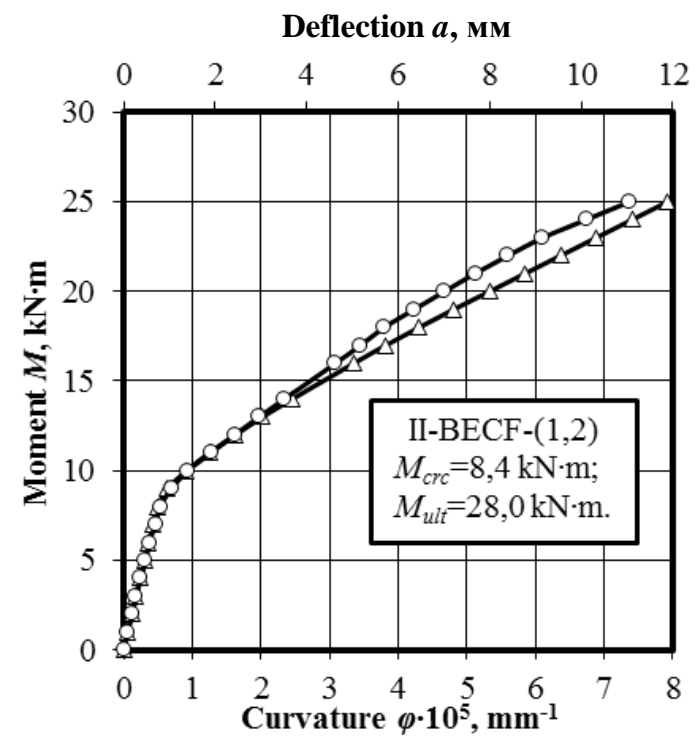

b)

a) - self-stressed beams of the series I;

b) - self-stressed beams of the series II

Fig. 3. Relations $\langle M-\varphi\rangle$ and $\langle M-a\rangle$ obtained on the static loading stage.

Test results obtained within loading of the selfstressed beams are presented in Table 6 and Table 7. 
Table 6. Failure modes and experimental values of cracking and ultimate loads obtained within self-stressed beams testing.

\begin{tabular}{|c|c|c|c|}
\hline Unit code & $\begin{array}{c}\text { Cracking } \\
\text { load (force) } \\
\boldsymbol{P}_{\text {cra }} \mathbf{k N} \\
\left(\boldsymbol{M}_{\text {cra }}\right. \\
\mathbf{k N} \cdot \mathbf{m})\end{array}$ & $\begin{array}{c}\text { Ultimate } \\
\text { load (force) } \\
\boldsymbol{P}_{\text {ult }} \mathbf{k N} \\
\left(\mathbf{M}_{\mathbf{u} / \mathrm{t}}\right. \\
\mathbf{k N} \cdot \mathbf{m})\end{array}$ & $\begin{array}{c}\text { Failure } \\
\text { mode }\end{array}$ \\
\hline I-BECS-(1) & $34(6,8)$ & $108(21,6)$ & \multirow{4}{*}{ «B» } \\
\hline I-BECS-(2) & $37,3(6,5)$ & $120(21,0)$ & \\
\hline I-BECS-(3) & $39,5(6,9)$ & $120(21,0)$ & \\
\hline I-BECS-(4) & $46,6(8,2)$ & $125,4(22,0)$ & \\
\hline II-BECF-(1) & $40,5(8,1)$ & $150(30,0)$ & \multirow{3}{*}{ «Sh» } \\
\hline II-BECF-(2) & $43,5(8,7)$ & $130(26,0)$ & \\
\hline II-BECF-(3) & $39,0(7,8)$ & $150(30,0)$ & \\
\hline
\end{tabular}

Table 7. Experimental values of the deflection and crack width obtained within self-stressed beams testing.

\begin{tabular}{|c|c|c|}
\hline Unit code & $\begin{array}{c}\text { Deflection } a, \\
\text { mm }\end{array}$ & $\begin{array}{c}\text { Crack width } \\
\left(w_{\max } / w_{m}\right), \mathrm{mm}\end{array}$ \\
\hline I-BECS-(1) & 2,3 & $0,1 / 0,1$ \\
\hline I-BECS-(2) & 2,7 & $0,15 / 0,07$ \\
\hline I-BECS-(3) & 2,9 & $0,1 / 0,09$ \\
\hline I-BECS-(4) & 3,2 & $0,1 / 0,1$ \\
\hline II-BECF-(1) & 4,9 & $0,7 / 0,59$ \\
\hline II-BECF-(2) & 4,6 & $0,6 / 0,38$ \\
\hline II-BECF-(3) & 4,6 & $0,6 / 0,47$ \\
\hline
\end{tabular}

For beams of series I and series II, initial tiny cracks occurred at the load of $44 \mathrm{kN}(7,1 \mathrm{kN} \cdot \mathrm{m})$ and $41 \mathrm{kN}$ $(8,2 \mathrm{kN} \cdot \mathrm{m})$ at average respectively in the pure bending region. After that in case of FRP reinforced beams, the slope of moment-curvature (moment-deflection) curves showed considerable drop and it was kept almost constant up to failure, as it is shown in Fig. 3. In case of steel reinforced beams, three characteristic branch sections with different slopes was observed: the first branch section - up to cracking; the second branch section - from cracking and up to reinforcing steel yielding; the third branch section - from reinforcing steel yielding and up to the failure (see Fig. 3). With increasing of the bending moment up to $24 \mathrm{kN} \cdot \mathrm{m}$, in the FRP reinforced beams, multiple inclined flexural shear cracks occurred outside the pure bending region and extended to a distance approximately $20 \mathrm{~mm}$ from the top surface of the beam. When applied load reached $143,3 \mathrm{kN}(28,7 \mathrm{kN} \cdot \mathrm{m})$ at average, diagonal tension flexural shear failure mode was reached, but to this time FRP reinforcing bars didn't reach its ultimate tensile strains (in accordance with test results: $\varepsilon_{r t, f r p}=0,933 \%$ ). Taking into account that FRP reinforced self-stressed beams reinforcement ratio was equal to $1,6 \%$ and $2,1 \%$ for II-BECF-(1,2) and II-BECF-(3) respectively, that is considerably higher of the both balanced reinforcement ratio $\left(\rho_{b a l}=0,3 \%\right)$ and recommended in accordance with [9] reinforcement ratio $1,4 \cdot \rho_{\text {bal }}=0,42 \%$. For the real reinforcement ratio of the tested beams, expected failure mode is due to crushing of the concrete in compression, but an observed failure mode had changed on the flexural shear without crushing of the concrete in compression. Moreover, registered within testing value of the ultimate moment was at average in 2 times higher than predicted value of the ultimate moment based on the mean and established in tests values of the materials charecteristics. In opposite to the FRP reinforced beams, failure mode and value of the ultimate load for steel reinforced self-stressed beams of series I was the same as it was predicted (ratio between predicted and established within loading ultimate bending moments was equal to 0,90 ).

Characteristic modes of failure and crack patterns for beams of the both series I and series II are shown in the Fig. 4.

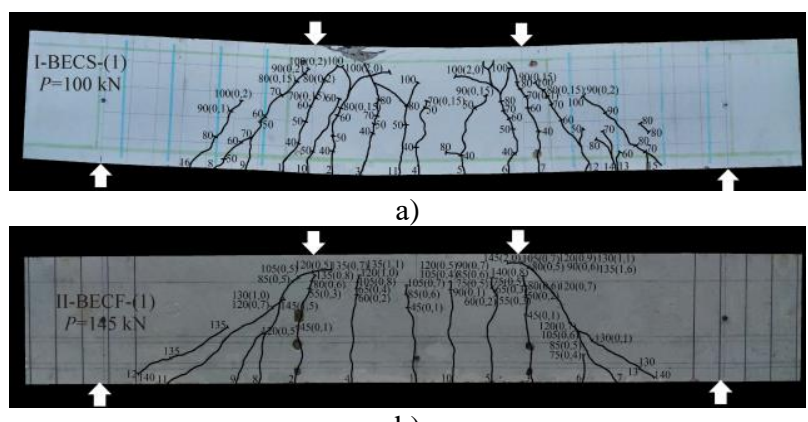

b)

a) - self-stressed beams of the series I; b) - self-stressed beams of the series II

Fig. 4. General view of the beam crack patterns after test.

Based on the analysis of the obtained experimental results, it can be stated, that initial early age stress-strain state obtained on the expansion stage influenced on the beams behavior during loading. It was observed that for the both series I and series II self-stressed beams cracking load was near $30 \%$ from the ultimate load (see Table 6). Flexural cracks development through the concrete cross-section depth was following: arised flexural cracks extended on the average depth about 180 $\mathrm{mm}$ and $195 \mathrm{~mm}(\approx 75 \%$ from cross-section depth) for series I and series II beams respectively and saved this position almost up to the failure on the background of the gradually increasing cracks number and its opening. This effect is explained that in the self-stressed structures initial compressive stresses are saved in concrete under the crack. An observed cracks patterns in the member tensile zone (see Fig. 4) with an average distance between cracks $60 \pm 15 \mathrm{~mm}$ indicated about practically uniform distribution of the stresses longwise reinforcing bars in tension, that is inherent for prestressed structures.

Taking into account that decompression strains is a parameter that allows assess effectiveness of the initial self-stressing and to predict its further influence on the crack behavior of the beams, this parameter $\left(\varepsilon_{\text {dec,exp }}\right)$ was obtained from experimental results analysis with diagram $\left\langle M-\varepsilon_{r t, x}\right\rangle$ utilizing and compared with the total tensile strains immediately before cracking measured on the depth of the reinforcement gravity center $-\varepsilon_{r t, c r c}$. 
This analysis of the self-stressing effectiveness was based on the assessment of the ratio between decompression strains $\left(\varepsilon_{\text {dec,exp }}\right)$ and total tensile strains $\left(\varepsilon_{r t, c r c}\right)$, that is presented in Table 8 .

Table 8. Experimental values of the concrete tensile strains on the depth of the reinforcement gravity center.

\begin{tabular}{|c|c|c|c|}
\hline Unit code & $\boldsymbol{\varepsilon}_{\text {dec,exp }}, \mathbf{\% o o}$ & $\boldsymbol{\varepsilon}_{r, \text { crc }}, \mathbf{\%}$ & $\mathbf{( 2 ) / ( 3 )}$ \\
\hline$(1)$ & $(2)$ & $(3)$ & $(4)$ \\
\hline I-BECS-(1) & 0,189 & 0,528 & 0,36 \\
\hline I-BECS-(2) & 0,241 & 0,542 & 0,44 \\
\hline I-BECS-(3) & 0,229 & 0,533 & 0,43 \\
\hline I-BECS-(4) & 0,312 & 0,658 & 0,47 \\
\hline II-BECF-(1) & 0,091 & 0,494 & 0,18 \\
\hline II-BECF-(2) & 0,095 & 0,480 & 0,20 \\
\hline II-BECF-(3) & 0,101 & 0,490 & 0,21 \\
\hline
\end{tabular}

As it is shown in Table 8, this ratio was at average 0,43 and 0,20 for self-stressed beams of the series I and series II respectively.

For effectiveness of the FRP reinforcing bars application in the prestressed (self-stressed) structures, $\left\langle M-\varepsilon_{r t, x}\right\rangle$ diagram was utilized (see Fig. 1). It was assessed from the experimental results, that before loading in the beams of series I and series II were obtained almost equal values of the moments, created by the precompression forces to the end of the expansion stage ( $M_{C E}$ was at average $3 \mathrm{kN} \cdot \mathrm{m}$ ), but at the same time decompression strains in case of FRP bars utilizing were less approximately in two times in comparison with decompression strains registered in self-stressed beams with steel reinforcement (see Table 8). It was stated, that up to decompression point, resultant force in tensile zone of the cross-section is sustained by the reinforcing bars only (at this stage concrete is under the initial compressive stresses). Taking into account that steel and FRP bars are characterized by the different values of modulus of elasticity (FRP bars modulus of elasticity $E_{\text {frpm }}=45,2 \mathrm{GPa}$, that was close to the concrete modulus of elasticity $E_{c m}=25,7 \mathrm{GPa}$ ), a different values of the moment increment was observed for the same levels of the longitudinal tensile strains in reinforcement (in case of FRP reinforcement, such increments were sufficiently less). To obtain equal values of the moment increments in case of FRP and steel bars utilizing, required area of FRP reinforcement have to be increased considerably and can be found based on the optimization procedure (it consists in the assessment of the FRP reinforcement axial stiffness, that is necessary to provide desired values of the moment increments within decompression stage as well as initial self-stresses at the expansion stage).

Nevertheless, it should be pointed that obtained selfstressing parameters in the members with FRP reinforcing bars not only lead to the cracking moment increasing, but change series II self-stressed beams postcracking behavior: a number of cracks, comparable with cracks number in series I self-stressed beams with steel reinforcing bars was observed ( $N=9$ and $N=12$ at average respectively), and maximum flexural crack width was not exceed $0,6 \mathrm{~mm}$ under the loading rate near $0,6 \cdot P_{u l t}$. It is necessary to point out, that in the design procedure of the reinforced self-stressed members, time-dependent losses (as a result of shrinkage and creep) of the initial prestress have to be assessed based on the extended model $[1,2]$.

\section{Conclusions}

Influence of the initial self-stressing on the concrete member behavior under the monotonically increasing loading was studied with the proposed diagram method. Obtained within self-stressing concrete expansion stressstrain state in the both steel and FRP reinforced selfstressed beams positively influenced on these members behavior under the applied load: an observed increasing of the crack resistance moment was equal to $33 \%$ and $28 \%$ for steel and FRP reinforced beams respectively, and, moreover, in concrete of all of the prepared selfstressed beams were achieved initial elastic compressive strains corresponding to the beams decompression strains within static loading. Nevertheless, a considerable difference in the behavior of the self-stressed beams with steel and FRP reinforcement was observed, especially up to decompression point: a sufficiently less values of the moment increment was observed in the FRP reinforced self-stressed beams (in comparison with steel reinforced beams) for the same levels of the longitudinal tensile strains in reinforcement because of the comparable low FRP bars modulus of elasticity, that is close to the concrete one. To obtain equal values of these moment increments in case of FRP and steel bars utilizing, required cross-sectional reinforcement ratio of FRP reinforcement can be found based on the optimization procedure consisted in the joint consideration of the proposed both MSDM [1, 2] and diagram method for certain design case.

\section{References}

1. Tur V., Herrador M.F., Semianiuk V., Proceedings of the fib Symposium 2017, 8 (2017)

2. Semianiuk V., Tur V., Herrador M.F., Paredes M., Constr. Build. Mat. J., 131, 11 (2017)

3. Kai-Cheng X., Meng-Cheng C., Fang Y., Open Civil Eng. J., 5, 6 (2011)

4. Ito H., Maruyama I., Tanimura M., Sato R., Adv. Concr. Technol. J., 2, 20 (2011)

5. Semianiuk V., Herrador M.F., Tur V., Proceedings of the VII Conference ACHE, 10 (2017)

6. Semianiuk V., Tur V., Solid States Phenomena J., 272, 6 (2018)

7. STB 1335-2002. Expansive cement: Technical specifications.

8. EN 196-1. Methods of testing cement - Part 1: Determination of strength.

9. CNR-DT 203/2006. Guide for the Design and Construction of Concrete Structures Reinforced with Fiber-Reinforced Polymer Bars. 